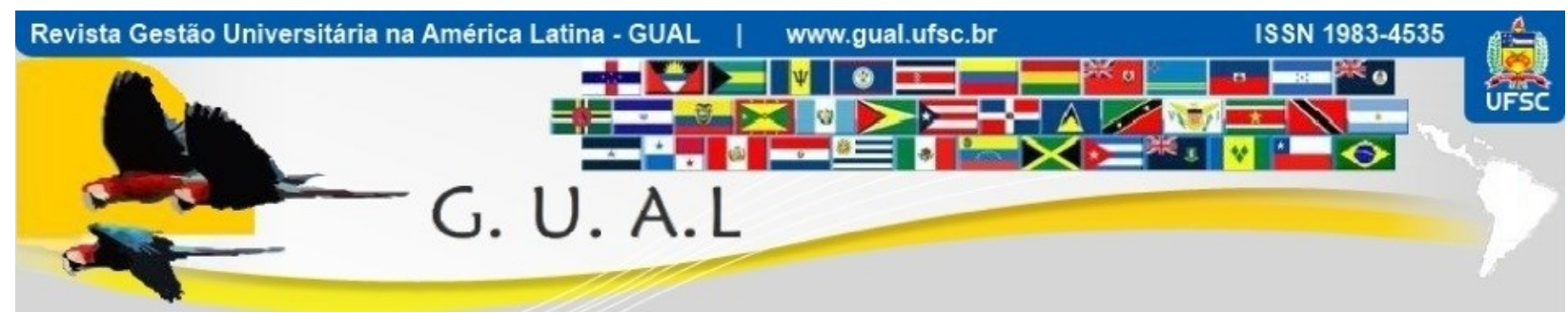

DOI: http://dx.doi.org/10.5007/1983-4535.2017v10n3p248

\title{
OS CONHECIMENTOS BÁSICOS DE CONTABILIDADE E ÁREAS AFINS: UM ESTUDO NAS UNIVERSIDADES POTIGUARES À LUZ DO CURRÍCULO MUNDIAL
}

\section{BASIC KNOWLEDGE IN ACCOUNTING AND RELATED AREAS: A STUDY AT POTIGUAR UNIVERSITIES UNDER THE GLOBAL CURRICULUM}

Kamila Kelly Paiva de Miranda Ferreira, Graduada

Universidade Federal Rural do Semi-Árido - UFERSA kamilamiranda02@,hotmail.com

Kléber Formiga Miranda, Mestre Universidade Federal Rural do Semi-Árido - UFERSA mirandakf@ufersa.edu.br

Thaiseany de Freitas Rêgo, Doutora Universidade Federal Rural do Semi-Árido - UFERSA thaiseany@ufersa.edu.br

Alexsandro Gonçalves da Silva Prado, Mestre Universidade Federal Rural do Semi-Árido - UFERSA alexsandro.prado@ufersa.edu.br

Recebido em $01 /$ março/2016

Aprovado em 14/julho/2017

Sistema de Avaliação: Double Blind Review

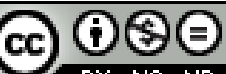

Esta obra está sob uma Licença Creative Commons Atribuição-Uso. 


\title{
RESUMO
}

O estudo se propõe a apresentar um panorama sobre o conteúdo ministrado pelas universidades potiguares, à luz do CM proposto pela ONU/UNCTAD/ISAR. Para tanto, utilizaram-se a pesquisa documental e análise de conteúdo das ementas de cada componente curricular oferecido pelas universidades potiguares, seja ele do tipo obrigatório ou optativo. Nessa conjuntura, adotou-se uma abordagem do tipo quali-quantitativa para a análise dos dados, uma vez que se utilizou da análise categorial das ementas e do estudo do nível de aderência do Projeto Pedagógico de Curso (PPC) ao CM. Destaca-se que, das 17 IES potiguares reconhecidas no Portal do e-MEC, foram selecionadas apenas aquelas que ofereciam cursos na modalidade presencial e configuraram-se como universidades propriamente ditas. No que diz respeito aos dados coletados, observa-se que há analogias nos conteúdos ministrados entre as universidades públicas $(\mu=27 \%)$ e privadas $(\mu=18 \%)$, principalmente quanto ao módulo referente à Contabilidade Básica $(21,83 \%)$. Destaca-se, ainda, que os componentes optativos influenciam na distribuição dos conteúdos curriculares oferecidos pelas IES e que, no geral, os resultados divergem entre as IES analisadas, o que denota a necessidade de reavaliação dos conteúdos distribuídos nos currículos oferecidos pelas universidades potiguares, no sentido de alinhar-se ao $\mathrm{CM}$ e convergir os módulos e conhecimentos ministrados pelos cursos de graduação em Ciências Contábeis.

Palavras chave: Educação Contábil. Conhecimento. Currículo Mundial.

\begin{abstract}
This study aims to present an overview of the content taught at Rio Grande do Norte universities, in light of the Global Curriculum proposed by the UN/UNCTAD/ISAR. In order to do that, the syllabus of each course at the universities underwent documentary research and content analyses; both elective and core courses were investigated. At this juncture, a qualiquantitative approach was adopted for data analysis, once we conducted a category-based analysis of the syllabi and utilized the study of the level of adherence of the Pedagogical Project of the Course to the Global Curriculum. It is important to note that out of the 17 certified higher learning institutions on the e-MEC Portal, only those which offered in-person courses and were actual universities were singled out for analysis. Regarding the gathered data, it could be observed that there are analogies between the contents that are taught in public $(\mu=27 \%)$ and private universities $(\mu=18 \%)$, mainly concerning the Basic Accounting course $(21,83 \%)$. Also, it could be perceived that elective courses have an influence on the distribution of the curricular activities available at the institutions and that, in general, the results differ among the ones that were analyzed. This further denotes the need to reassess curricular contents at the universities of Rio Grande do Norte so as to align these contents with those of the Global Curriculum and have the modules taught in Accounting Schools converge.
\end{abstract}

Keywords: Accounting Education. Knowledge. Global Curriculum. 


\section{INTRODUÇÃO}

A contabilidade evolui de acordo com avanço econômico e social. Segundo Peleias et al. (2007), as mudanças ocorridas no ambiente político, social e econômico, tem estimulado o desenvolvimento de estudos sobre o processo formativo e o campo de atuação profissional do Contador. Isso porque, cabe ao mesmo, o papel de acompanhar o que está ocorrendo no ambiente, principalmente no que diz respeito às alterações observadas nas leis e normas vigentes no intuito de revelar as influências econômicas no patrimônio das empresas.

Segundo Faria e Queiroz (2009), as habilidades e competências transmitidas aos estudantes que se encontram em processo formativo, variam de acordo com a formação do corpo docente e desenvolvimento regional. Logo, o processo de ensino-aprendizagem se preocupa em alinhar as práticas desenvolvidas em sala, com as exigências do campo de atuação. Nessa perspectiva, a transmissão de conhecimentos sobre as normas e procedimentos de contabilidade é essencial para o exercício profissional.

Destaca-se que as Instituições de Ensino Superior (IES) preocupadas em formar profissionais capacitados para o exercício profissional do Contador em nível global, precisam contemplar discussões mais amplas. Nessa conjuntura, o conhecimento sobre normas, procedimentos e estratégias a serem adotadas diante de cenários otimistas, estáveis e pessimistas, torna-se essencial. Apesar disso, Riccio e Sakata (2004) comentam que isso só é possível, quando os mesmos desenvolvem senso-crítico e se mostram capazes de solucionar problemas rotineiros.

Campos e Lemes (2012) consideram que as mudanças do ambiente, tem estimulado o desenvolvimento de estratégias de ensino voltadas para a atuação na área contábil. Nesse contexto, a Organização das Nações Unidas (ONU) tem exercido um papel importante no processo formativo e propõe um Currículo Mundial (CM). Para tanto, a mesma coordenou a United Nations Conference on Trade and Development (UNCTAD, 1999), conferência que discutiu sobre a transmissão de conhecimentos relacionados ao International Standards of Accounting and Reporting (ISAR).

A formação de profissionais devidamente capacitados para a atuação profissional é essencial para o desenvolvimento econômico de um país (PELEIAS et al., 2007). Por conseguinte, a concepção de um Projeto Pedagógico de Curso (PPC), aliado às demandas econômicas, financeiras e sociais, é uma estratégia essencial para a formação de indivíduos devidamente capacitados para o exercício profissional (GUIMARÃES et al., 2010). Destaca- 
se que o referido instrumento, deve acompanhar as mudanças ocorridas nas políticas educacionais, bem como a Lei de Diretrizes e Bases da Educação Nacional (Lei n. ${ }^{\circ}$ 9.394/1996).

Considerando que há alguns estudos preocupados em tratar sobre questões de similaridade entre as disciplinas das IES e o CM (RICCIO; SAKATA, 2004; MAGALHÃES; ANDRADE, 2006; ERFURTH; DOMINGUES, 2008; CZESNAT; CUNHA; DOMINGUES, 2009; SEGANTINI et al., 2010; CAMPOS; LEMES, 2012), constatou-se que pouco se discute sobre os conteúdos programáticos propostos no PPC. Logo, o presente trabalho se propõe a desenvolver um panorama conceitual, sobre o que se discute em termos de conhecimentos básicos de contabilidade e áreas afins.

A discussão sobre como ocorre o processo formativo dos estudantes de Contabilidade é importante, uma vez que se reflete na atuação profissional (FARIA; QUEIROZ, 2009). Logo, o presente estudo se utilizada do paradigma interpretativista, para responder ao seguinte problema de pesquisa: "Qual o panorama do conteúdo ministrado pelas universidades potiguares, à luz do CM proposto pela ONU/UNCTAD/ISAR?” Seguindo essa lógica, adotase o contexto local, bem como os conhecimentos básicos de contabilidade e áreas afins, como medidas de recorte apropriadas para retratar o nível de aderência das IES ao CM e as demandas da à Lei n. ${ }^{\circ}$ 11.638/2007 (CAVALCANTE et al., 2011).

\section{REFERENCIAL TEÓRICO}

\subsection{AMBIENTE CONTÁBIL}

Oliveira et al. (2011) destacam que a contabilidade vem ganhando cada vez mais espaço, em meio as discussões econômicas, administrativas e legais. Isso ocorre paralelamente, com as mudanças legais e normativas, observadas no campo de atuação profissional do Contador. Para Antunes et al. (2012), isso é perceptível na Lei n. ${ }^{\circ}$ 11.638/2007, Lei n. ${ }^{\circ} 11.941 / 2009$, Lei n. ${ }^{\circ}$ 12.249/2010 e nos procedimentos emitidos pelo Comitê de Pronunciamentos Contábeis (CPC), quanto ao registro e divulgação de informações econômicas, financeiras e patrimoniais.

Destaca-se que o foco dos profissionais de contabilidade, consiste em preparar e divulgar informações úteis para o processo de tomada de decisão dos stakeholders. Para tanto, as mesmas são revestidas de características qualitativas, que refletem a utilidade, fidedignidade, relevância, compreensibilidade, comparabilidade, verificabilidade e 


\section{OS CONHECIMENTOS BÁSICOS DE CONTABILIDADE E ÁREAS AFINS: UM ESTUDO NAS \\ UNIVERSIDADES POTIGUARES À LUZ DO CURRÍCULO MUNDIAL \\ DOI: http://dx.doi.org/10.5007/1983-4535.2017v10n3p248}

tempestividade da informação. Logo, oferecer uma formação pautada nesses aspectos e no uso de novas tecnologias, é essencial, para tornar a profissão contábil dinâmica, moderna e insubstituível nas organizações (MERLO, 2006).

Considerando que as relações de negócio são essenciais para a economia, salienta-se que o processo de harmonização das práticas e procedimentos de contabilidade, estimula o desenvolvimento de novas trocas. As mesmas se revestem de benefícios que propiciam a expansão do mercado de capitais, o processo de internacionalização e a ampliação das possibilidades de atuação em multinacionais. Antunes et al. (2012) apontam que ao se assumir a primazia da essência sobre a forma, também é possível gerar informações fidedignas, transparentes e confiáveis.

Destaca-se que o registro e tratamento da informação contábil, permite reconhecer os eventos a serem registrados, tanto em termos formais, como observando a realidade econômica. Segundo Merlo (2006), a preocupação dos profissionais de contabilidade com a produção de informações úteis, possibilita o atendimento das demandas internas e externas à organização. O que tem estimulado os profissionais da área contábil, a assumirem o papel de gerenciador, consultor e detentor de informações, capazes de auxiliar no processo de tomada de decisão.

\subsection{O ENSINO DA CONTABILIDADE NO BRASIL}

Segundo Peleias e Bacci (2004), o primeiro curso nacional sobre as práticas comerciais foi criado em 1809, sendo denominado de "Aulas de comércio" ou "Aulas práticas". O mesmo surgiu com o propósito de atender as necessidades dos comerciantes locais, em registrar suas operações diárias, de compra e venda. Em 1870, com a promulgação do Decreto Imperial n. ${ }^{\circ} 4.475$, os mesmos passaram a ser tratados como profissionais liberais, sendo denominados como "Guarda-livros".

A primeira instituição nacional a oferecer formação técnica na área contábil foi a Escola de Comércio Álvares Penteado, fundada em 1902, na cidade de São Paulo (IUDÍCIBUS, 2004). Segundo Schmidt (2000), essa escola oferecia cursos de nível técnico para "Guarda-livros" e "Perito-contador". Laffin (2005) comenta que os cursos em nível de graduação só iniciaram em 1945, após o Decreto Lei n. ${ }^{\circ}$ 7.988, com a criação da Faculdade de Ciências Econômicas e Administrativas (FEA) da Universidade de São Paulo (USP). 


\section{OS CONHECIMENTOS BÁSICOS DE CONTABILIDADE E ÁREAS AFINS: UM ESTUDO NAS \\ UNIVERSIDADES POTIGUARES À LUZ DO CURRÍCULO MUNDIAL \\ DOI: http://dx.doi.org/10.5007/1983-4535.2017v10n3p248}

O primeiro curso de pós-graduação e grupo de pesquisa, na área contábil, foi criado quando os docentes passaram a se dedicar a orientação de trabalhos em nível acadêmico (MAGAlHÃES; ANDRADE, 2006). Porém, com o questionamento da qualidade dos egressos, o ensino passou por um processo de mudança significativo, alinhando as práticas de ensino as demandas comerciais (GUIMARÃES et al. 2009). Campos e Lemes (2012) comentam que isso foi reforçado em 1999, quando o International Standards of Accounting and Reporting (ISAR) realizou uma sessão especial, para tratar sobre a implantação do CM.

O ISAR instituiu em suas discussões, o Guideline on National Requirements for the Qualification of Professional Accountants - TD5 e o Global Curriculum for the Professional Education of Professional Accountants - TD6. O primeiro trata de um programa de estudos, normas e requisitos de qualificação para os profissionais de contabilidade, ao passo que o segundo aborda sobre o currículo ideal para o processo formativo. Os mesmos foram elaborados com o intuito de alinhar os conteúdos ministrados pelas Instituições de Ensino Superior (IES), sendo revisado em 2003 (CAMPOS; LEMES, 2012).

Considerando os aspectos enumerados, a Organização das Nações Unidas (ONU) propôs o CM, um modelo formativo voltado para a disseminação e inserção de conteúdos internacionais (SILVA; RÊGO, 2014). Marin, Lima e Casa Nova (2011), destacam que no Brasil a FUCAPE Business School foi à primeira IES a alinhar seus componentes curriculares a essa nova prerrogativa e a formar o Contador Global. O propósito consistiu em prepará-los para atuar em qualquer ambiente, o que estimulou o desenvolvimento de alguns estudos: (MAGALHÃES; ANDRADE, 2006: IES Piauienses; CZESNAT; CUNHA; DOMINGUES, 2009: IES catarinenses; SEGANTINI et al., 2010: Universidades do Mercosul; CAVALCANTE et al., 2011: Univerisidades Federais do Brasil; ZONATTO; DANI; DOMINGUES, 2011: IES do Rio Grande do Sul; SANTOS; DOMINGUES; RIBEIRO, 2012: IES paranaenses). Os estudos identificam similaridade entre o Currículo Mundial de menos de $50 \%$ a $91,73 \%$, demonstrando a diferença entre os currículos no Brasil.

Os estudos nacionais sobre o processo formativo tratam sobre a questão da aderência das IES as propostas e diretrizes requeridas pelo $\mathrm{CM}$, para reduzir as barreiras de atuação em nível internacional (CZESNAT; CUNHA; DOMINGUES, 2009). Segundo Silva e Rêgo (2014), isso ocorre em razão das proposições emanadas pelo Ministério da Educação (MEC), mediante a Resolução CNE/CES n. ${ }^{0}$ 10/2004, e a "Proposta Nacional de Conteúdo para os cursos de graduação em Ciências Contábeis", editada pelo Conselho Federal de Contabilidade 
(CFC). Os referidos instrumentos fundamentam a construção de Projetos Pedagógicos de Curso (PPC) e apresentam as principais prioridades, reflexões e necessidades dos cursos de graduação (GUIMARÃES et al., 2009).

\subsection{O CAMPO DE ATUAÇÃO PROFISSIONAL}

Com o intuito de alinhar o processo formativo oferecido pelos cursos de graduação em Ciências Contábeis à demanda internacional, as IES incluíram o componente curricular de “Contabilidade internacional” (CZESNAT; CUNHA; DOMINGUES, 2009). Destaca-se que esse foi o primeiro esforço nacional a favor da convergência as normas internacionais, seguido pela promulgação da Lei n. ${ }^{\circ}$ 11.638/2007. Segundo Viana e Sousa (2012), ao aderir a essas normas, as empresas tendem a se beneficiar com a redução do custo de capital e melhorias na qualidade da informação fornecida.

De acordo com Fernandes et al. (2011), a convergência as normas internacionais provoca mudanças significativas nas atividades de ensino, uma vez que interfere na linguagem contábil e nas práticas transmitidas em sala de aula. Isso é perceptível ao se analisar o conteúdo de cada procedimento, registro e demonstração contábil, elaborado antes e após a adoção dos pronunciamentos emitidos pelo CPC. Nesse contexto, Viana e Sousa (2012) destacam que empresas internacionais, com filiais no Brasil, tem se interessado em contratar profissionais com conhecimentos adequados sobre os procedimentos e práticas internacionais.

Albuquerque e Carvalho (2007) apontam que cabe aos profissionais da contabilidade, o papel de acompanhar as mudanças ocorridas no ambiente, nas atividades de ensino e no campo de atuação profissional. Considerando isso, destaca-se que as possibilidades de atuação, em um contexto global, são inúmeras (CZESNAT; CUNHA; DOMINGUES, 2009), como destacado pela Resolução CFC n. ${ }^{\circ}$ 560/1983: Analista, assessor, assistente, auditor interno e externo, conselheiro, consultor, controlador de arrecadação, controller, educador, dentre outros.

Compreendendo que há diversas possibilidades de atuação na área Contábil, cabe ao egresso buscar as habilidades e competências requeridas para a construção de seu conhecimento e desenvolvimento de suas atividades diárias (VEIGA, 2004). No Brasil, segundo Albuquerque e Carvalho (2007), a classe está representada pelo CFC, entidade responsável pelo registro profissional, processo de educação continuada e acompanhamento 
de suas atividades. Valeretto (2010) comenta que essa entidade também tem um papel importante no processo formativo, pois reconhece a rotina do campo de atuação nacional e pode auxiliar na indicação de quais conteúdos, obscuros na Resolução CNE/CES n. ${ }^{\circ}$ 10/2004 e no CM, podem ser implantados nos currículos.

Para Rêgo e Andrade (2010), a preocupação com o processo formativo deve ir além dos conteúdos ministrados em sala de aula, uma vez que precisa transmitir aos egressos, uma postura ética e moral, fundamentada nos princípios de liderança, interação e senso crítico. Nogueira e Fari (2007) destacam que o egresso deve ser capaz de acompanhar os avanços tecnológicos, solucionar problemas e interpretar relatórios gerenciais, para se tornar um profissional capaz de auxiliar no processo de tomada de decisão. Logo, o campo de atuação profissional exige uma postura mais arrojada e dinâmica, em termos de construção do conhecimento contábil (PIRES; OTT; DAMACENA, 2009).

\section{METODOLOGIA DA PESQUISA}

A presente pesquisa configura-se como do tipo exploratória e descritiva (GIL, 2002). Nessa perspectiva, busca-se apresentar um panorama sobre o conteúdo ministrado nas universidades potiguares, em relação ao CM. Além disso, trata mais especificamente sobre a identificação e descrição sobre o nível de aderência das IES norte-rio-grandenses ao Bloco de Conhecimentos Básicos de Contabilidade e Áreas Afins (CBCAA).

O estudo configura-se também como do tipo documental (MARCONI; LAKATOS, 2003), uma vez que adota o PPC dos cursos de Contabilidade como fonte de dados, e se vale da análise de conteúdo (GIL, 2002). Para tanto, os projetos dos cursos foram analisados, com o intuito de identificar as ementas dos componentes curriculares ofertados. Em seguida, procedeu-se com a segregação e apreciação do conteúdo do componente curricular (CC) de cada ementa, de caráter obrigatório (OB) e optativo (OP), de modo a confrontá-los com os conhecimentos recomendados pelo $\mathrm{CM}$.

A amostra foi estabelecida, considerando as IES que oferecem o curso de graduação em Ciências Contábeis no Estado do Rio Grande do Norte (RN), na modalidade presencial. Para tanto, considerou-se as informações coletadas no Portal do e-MEC, em janeiro de 2013, para identificar a IES, curso e modalidade existentes na região. Nesse momento, foram identificadas 17 IES, das quais foram selecionadas apenas aquelas que se posicionavam como 


\section{OS CONHECIMENTOS BÁSICOS DE CONTABILIDADE E ÁREAS AFINS: UM ESTUDO NAS \\ UNIVERSIDADES POTIGUARES À LUZ DO CURRÍCULO MUNDIAL \\ DOI: http://dx.doi.org/10.5007/1983-4535.2017v10n3p248}

universidades e que além da atividade de ensino, desenvolviam ações de pesquisa e extensão (RÊGO; ANDRADE, 2010).

Com o levantamento das informações pertinentes a cada curso, foi possível selecionar instituições que abrangem as quatro Mesorregiões do RN e que contemplam questões de regionalidade em seus currículos. Finalizada essa etapa, procedeu-se com a coleta do PPC de cada curso, em mídia digital, no Portal de cada IES ou por endereço eletrônico. De posse do PPC de cada curso, procedeu-se com as etapas da análise de conteúdo, como discutido por Bardin (2009): a) Pré-análise; b) Exploração do material; e, c) Tratamento dos resultados.

Em uma análise categorial, a codificação da análise de conteúdo compreende três escolhas: a das unidades (o recorte), a da regra de contagem (a enumeração) e a escolha das categorias (BARDIN, 2009). Destaca-se que a maioria dos procedimentos utilizados na análise de conteúdo, refere-se a um processo de categorização, composto por classes ou rubricas. Na presente pesquisa, a mesma foi realizada com o intuito de fornecer uma simplificação dos dados brutos, em face do conteúdo referente aos nove Módulos apresentados no bloco de CBCAA do CM, como pode ser visualizado no Quadro 1.

Quadro 1 Módulos e conhecimentos referentes ao bloco de CBCAA

\begin{tabular}{|c|c|}
\hline MÓDULOS & $\begin{array}{l}\text { CONHECIMENTOS } \\
\end{array}$ \\
\hline Contabilidade Básica & $\begin{array}{l}\text { Contabilidade Geral; História do Pensamento Contábil; Introdução à } \\
\text { Análise de Balanços; Normas da Profissão Contábil e Teoria da } \\
\text { Contabilidade }\end{array}$ \\
\hline Contabilidade Financeira & $\begin{array}{l}\text { Contabilidade Ambiental; Contabilidade Avançada e Contabilidade } \\
\text { Comercial }\end{array}$ \\
\hline $\begin{array}{l}\text { Contabilidade Financeira } \\
\text { Avançada }\end{array}$ & Contabilidade Avançada Aplicada e Tópicos Contemporâneos \\
\hline Contabilidade Gerencial & $\begin{array}{l}\text { Análise de Balanços Avançados; Análise de Custos e Contabilidade de } \\
\text { Custos }\end{array}$ \\
\hline $\begin{array}{l}\text { Fundamentos de } \\
\text { Auditoria }\end{array}$ & $\begin{array}{l}\text { Auditoria de Sistemas Informatizados; Avaliação e Planejamento de } \\
\text { Auditoria; Normas Nacionais e Internacionais de Auditoria e Princípios e } \\
\text { Conceitos de Auditoria }\end{array}$ \\
\hline $\begin{array}{l}\text { Integração dos } \\
\text { Conhecimentos }\end{array}$ & Estudos de Casos \\
\hline Legislação Comercial & $\begin{array}{l}\text { Direito Comercial; Direito Público e Privado; Legislação } \\
\text { Social/Trabalhista; Legislação Societária }\end{array}$ \\
\hline $\begin{array}{l}\text { Sistemas de Informação } \\
\text { Contábil }\end{array}$ & $\begin{array}{l}\text { Desenvolvimento de Sistemas de Informação Contábil; Funcionamento } \\
\text { dos Programas Informáticos Comerciais; Sistemas de Informações } \\
\text { Gerenciais }\end{array}$ \\
\hline Tributação & Contabilidade Tributária e Direito Tributário \\
\hline
\end{tabular}

Fonte: Adaptado da UNCTAD (2003). 


\section{OS CONHECIMENTOS BÁSICOS DE CONTABILIDADE E ÁREAS AFINS: UM ESTUDO NAS \\ UNIVERSIDADES POTIGUARES À LUZ DO CURRÍCULO MUNDIAL \\ DOI: http://dx.doi.org/10.5007/1983-4535.2017v10n3p248}

Destaca-se que os referidos conhecimentos foram pesquisados nas ementas das IES potiguares, que ofereciam o curso de Contabilidade, nas condições especificadas, das quais se extraiu os termos adequados para a análise do estudo. Em seguida, procedeu-se com a sua organização por módulo, conhecimento e tipo de componente curricular oferecido. Por conseguinte, os dados foram analisados com o auxílio de uma Planilha eletrônica dinâmica (Microsoft Office Excel® 2010), sendo os mesmos validados com o auxílio de docentes com amplos conhecimentos sobre o processo de ensino-aprendizagem e construção de PPC, o que resultou em discussões sobre a natureza de cada termo observado.

\section{APRESENTAÇÃO E DISCUSSÃO DOS RESULTADOS}

\subsection{MÓDULOS OFERECIDOS PELAS UNIVERSIDADES POTIGUARES}

O módulo de Contabilidade Básica, apresentado na Tabela 1, totaliza 172 termos encontrados nas ementas das universidades potiguares, sendo essa a categoria de maior representatividade entre no bloco de CBCAA. Destaca-se que a mesma contempla assuntos de caráter introdutório, essenciais para o processo de ensino-aprendizagem e andamento do curso. Sequencialmente, o módulo de Contabilidade Financeira, com 142 termos, representa a continuidade dos assuntos estudados no módulo anterior, de uma forma mais aprofundada.

Tabela 1 Distribuição dos termos pelos módulos oferecidos nas universidades potiguares

\begin{tabular}{l|c|c|c|c|c|c}
\hline \multicolumn{1}{c|}{ MÓDULOS } & $\begin{array}{c}\text { UFERS } \\
\text { A }\end{array}$ & UERN & UFRN & UnP & TOTAL & \% \\
\hline Contabilidade Básica & 45 & 38 & 59 & 30 & $\mathbf{1 7 2}$ & 21,8 \\
\hline Contabilidade Financeira & 43 & 44 & 28 & 27 & $\mathbf{1 4 2}$ & 18,0 \\
\hline Contabil. Financeira Avançada & 12 & 8 & 16 & 3 & $\mathbf{3 9}$ & 4,9 \\
\hline Contabilidade Gerencial & 32 & 20 & 33 & 12 & $\mathbf{9 7}$ & 12,3 \\
\hline Fundamentos de Auditoria & 26 & 10 & 16 & 7 & $\mathbf{5 9}$ & 7,5 \\
\hline Integração dos Conhecimentos & 8 & 10 & 1 & 0 & $\mathbf{1 9}$ & 2,4 \\
\hline Legislação Comercial & 25 & 42 & 22 & 29 & $\mathbf{1 1 8}$ & 15,0 \\
\hline Sistemas de Informação & & & & & & \\
Contábil & 8 & 16 & 15 & 18 & $\mathbf{5 7}$ & 7,2 \\
\hline Tributação & 21 & 24 & 25 & 15 & $\mathbf{8 5}$ & 10,8 \\
\hline \multicolumn{1}{c|}{ TOTAL } & $\mathbf{2 2 0}$ & $\mathbf{2 1 2}$ & $\mathbf{2 1 5}$ & $\mathbf{1 4 1}$ & $\mathbf{7 8 8}$ & - \\
\hline
\end{tabular}

Fonte: Dados da pesquisa (2014).

Os dados revelam que $77 \%$ do conteúdo ministrados pelas IES estão distribuídos entre os módulos de Contabilidade Básica (21,8\%), Contabilidade Financeira (18,0\%), Legislação Comercial (15,0\%), Contabilidade Gerencial (12,3\%) e Tributação (10,8\%). Pela distribuição dos termos, a UFERSA se destaca por priorizar o desenvolvimento de pontos inerentes aos 
módulos de Contabilidade Básica (45), Contabilidade Financeira (43), Contabilidade Gerencial (32) e Fundamentos de Auditoria (26). Isso corrobora com o estudo de Czesnat, Cunha e Rodrigues (2009) e Marin, Lima e Casa Nova (2011), quanto à consolidação dos conteúdos de Contabilidade Básica nas IES nacionais e formação de egressos com um senso crítico alinhado as prerrogativas do CM.

\subsection{DISTRIBUIÇÃO DOS CONHECIMENTOS MINISTRADOS}

A frequência (f) com que cada termo é apresentado entre os conhecimentos oferecidos pelas IES pesquisadas corresponde a distribuição dos conteúdos dispostos no PPC, em relação aos módulos propostos pelo CM. Para tanto, na Tabela 2 são apresentados os conhecimentos propostos pelo módulo de Contabilidade Básica, observando questões de similaridade com o $\mathrm{CM}$, contemplando questões essenciais para o processo formativo, permitindo alinhar os aspectos históricos, teóricos e normativos, a prática exigida no campo de atuação profissional.

Tabela 2 Distribuição dos conhecimentos no módulo de Contabilidade Básica

\begin{tabular}{|c|c|c|c|c|c|c|c|c|c|c|c|}
\hline \multirow{2}{*}{ CONHECIMENTOS } & \multirow{2}{*}{$\mathrm{CC}$} & \multicolumn{2}{|c|}{ UFERSA } & \multicolumn{2}{|c|}{ UERN } & \multicolumn{2}{|c|}{ UFRN } & \multicolumn{2}{|c|}{ UnP } & \multicolumn{2}{|c|}{ TOTAL } \\
\hline & & $f$ & $\%$ & $f$ & $\%$ & $f$ & $\%$ & $f$ & $\%$ & $f$ & $\%$ \\
\hline \multirow{3}{*}{ Contabilidade Geral } & OB & 27 & 60,0 & 13 & 34,2 & 33 & 55,9 & 12 & 40,0 & \multirow{3}{*}{90} & \multirow{3}{*}{52,3} \\
\hline & $\mathrm{OP}$ & 1 & 2,2 & 3 & 7,9 & 1 & 1,7 & 0 & 0,0 & & \\
\hline & Total & 28 & - & 16 & - & 34 & - & 12 & - & & \\
\hline \multirow{3}{*}{$\begin{array}{l}\text { História do } \\
\text { Pensamento Contábil }\end{array}$} & OB & 5 & 11,1 & 1 & 2,6 & 6 & 10,2 & 6 & 20,0 & \multirow{3}{*}{19} & \multirow{3}{*}{11,0} \\
\hline & $\mathrm{OP}$ & 0 & 0,0 & 1 & 2,6 & 0 & 0,0 & 0 & 0,0 & & \\
\hline & Total & 5 & - & 2 & - & 6 & - & 6 & - & & \\
\hline \multirow{3}{*}{$\begin{array}{l}\text { Introdução à Análise } \\
\text { de Balanços }\end{array}$} & OB & 2 & 4,4 & 4 & 10,5 & 4 & 6,8 & 5 & 16,7 & \multirow{3}{*}{16} & \multirow{3}{*}{9,3} \\
\hline & OP & 0 & 0,0 & 0 & 0,0 & 1 & 1,7 & 0 & 0,0 & & \\
\hline & Total & 2 & - & 4 & - & 5 & - & 5 & - & & \\
\hline \multirow{3}{*}{$\begin{array}{l}\text { Normas da Profissão } \\
\text { Contábil }\end{array}$} & $\mathrm{OB}$ & 4 & 8,9 & 1 & 2,6 & 3 & 5,1 & 1 & 3,3 & \multirow{3}{*}{10} & \multirow{3}{*}{5,8} \\
\hline & OP & 0 & 0,0 & 0 & 0,0 & 1 & 1,7 & 0 & 0,0 & & \\
\hline & Total & 4 & - & 1 & - & 4 & - & 1 & - & & \\
\hline \multirow{3}{*}{$\begin{array}{l}\text { Teoria da } \\
\text { Contabilidade }\end{array}$} & $\mathrm{OB}$ & 6 & 13,3 & 4 & 10,5 & 10 & 16,9 & 6 & 20,0 & \multirow{3}{*}{37} & \multirow{3}{*}{21,5} \\
\hline & OP & 0 & 0,0 & 11 & 28,9 & 0 & 0,0 & 0 & 0,0 & & \\
\hline & Total & 6 & - & 15 & - & 10 & - & 6 & - & & \\
\hline TOTAL $(f)$ & - & \multicolumn{2}{|c|}{45} & \multicolumn{2}{|c|}{38} & \multicolumn{2}{|c|}{59} & \multicolumn{2}{|c|}{30} & \multicolumn{2}{|c|}{172} \\
\hline
\end{tabular}

Fonte: Dados da pesquisa (2014).

Os resultados apontam que predomina o desenvolvimento de conteúdos inerentes a Contabilidade Geral (52,3\%), Teoria da Contabilidade (21,5\%) e História do Pensamento Contábil (11,0\%). Individualmente, observa-se a UFRN com um maior número de termos similares ao CM concentradas em componentes obrigatórios (94,9\%). A UFERSA $(97,7 \%)$ e a UERN (60,4\%), também concentram suas discussões do módulo de Contabilidade Básica, 


\section{OS CONHECIMENTOS BÁSICOS DE CONTABILIDADE E ÁREAS AFINS: UM ESTUDO NAS \\ UNIVERSIDADES POTIGUARES À LUZ DO CURRÍCULO MUNDIAL \\ DOI: http://dx.doi.org/10.5007/1983-4535.2017v10n3p248}

entre os componentes obrigatórios. A UnP destaca-se por disponibilizar todos os seus conhecimentos do módulo de Contabilidade Básica (30\%), como componentes obrigatórios.

Em se tratando do módulo de Contabilidade Financeira, que trata sobre discussões intermediárias, inerentes as operações comerciais, bem como as práticas envolvendo o meio ambiente e a análise superficial das demonstrações, também foram levantadas algumas questões de similaridade e dispostas na Tabela 3.

Tabela 3 Distribuição dos conhecimentos no módulo de Contabilidade Financeira

\begin{tabular}{|c|c|c|c|c|c|c|c|c|c|c|c|}
\hline \multirow{2}{*}{ CONHECIMENTOS } & \multirow{2}{*}{$\mathbf{C C}$} & \multicolumn{2}{|c|}{ UFERSA } & \multicolumn{2}{|c|}{ UERN } & \multicolumn{2}{|c|}{ UFRN } & \multicolumn{2}{|c|}{ UnP } & \multicolumn{2}{|c|}{ TOTAL } \\
\hline & & $f$ & $\%$ & $f$ & $\%$ & $f$ & $\%$ & $f$ & $\%$ & $f$ & $\%$ \\
\hline \multirow{3}{*}{$\begin{array}{l}\text { Contabilidade } \\
\text { Ambiental }\end{array}$} & OB & 9 & 20,9 & 6 & 13,6 & 0 & 0,0 & 5 & 18,5 & \multirow{3}{*}{39} & \multirow{3}{*}{27,5} \\
\hline & $\mathrm{OP}$ & 0 & 0,0 & 15 & 34,1 & 0 & 0,0 & 4 & 14,8 & & \\
\hline & Total & 9 & - & 21 & - & $\mathbf{0}$ & - & 9 & - & & \\
\hline \multirow{3}{*}{$\begin{array}{l}\text { Contabilidade } \\
\text { Avançada }\end{array}$} & $\mathrm{OB}$ & 11 & 25,6 & 5 & 11,4 & 9 & 32,1 & 1 & 3,7 & \multirow{3}{*}{27} & \multirow{3}{*}{19,0} \\
\hline & $\mathrm{OP}$ & 0 & 0,0 & 1 & 2,3 & 0 & 0,0 & 0 & 0,0 & & \\
\hline & Total & 11 & - & 6 & - & 9 & - & 1 & - & & \\
\hline \multirow{3}{*}{$\begin{array}{l}\text { Contabilidade } \\
\text { Comercial }\end{array}$} & $\mathrm{OB}$ & 22 & 51,2 & 15 & 34,1 & 19 & 67,9 & 17 & 63,0 & \multirow{3}{*}{76} & \multirow{3}{*}{53,5} \\
\hline & $\mathrm{OP}$ & 1 & 2,3 & 2 & 4,5 & 0 & 0,0 & 0 & 0,0 & & \\
\hline & Total & 23 & - & 17 & - & 19 & - & 17 & - & & \\
\hline TOTAL $(f)$ & - & \multicolumn{2}{|c|}{43} & \multicolumn{2}{|c|}{44} & \multicolumn{2}{|c|}{28} & \multicolumn{2}{|c|}{27} & \multicolumn{2}{|c|}{142} \\
\hline
\end{tabular}

Fonte: Dados da pesquisa (2014).

Os resultados apontam que no módulo de Contabilidade Financeira, as universidades potiguares concentram seus conhecimentos em conteúdos voltados a Contabilidade Comercial (53,5\%). Outro ponto que chama atenção é que embora os esforços da UERN volte-se também a Contabilidade Ambiental (47,7\%), a maior parte das discussões sobre o meio ambiente concentra-se em componentes optativos (34,1\%). Já na UFRN, não é observada nenhuma discussão sobre práticas de gestão ou procedimentos de registro de operações envolvendo o meio ambiente e na UnP destaca-se a distribuição de poucos conteúdos sobre Contabilidade Avançada (3,7\%), em sua proposta formativa.

As constatações enumeradas são preocupantes, considerando o atual cenário econômico, político, social e ambiental, marcado pela inclusão de práticas de Contabilidade Ambiental, nas operações das empresas. Além de questões legais e normativas, inerentes a questão de combinação de negócios, fusões, aquisições e outras operações de maior complexidade.

Quanto ao módulo de Contabilidade Financeira Avançada, que trata sobre práticas e procedimentos contábeis mais aprofundados, constatou-se predomina a discussões de pontos inerentes a Contabilidade Avançada Aplicada (74,4\%), como ilustrado na Tabela 4. Ao 


\section{OS CONHECIMENTOS BÁSICOS DE CONTABILIDADE E ÁREAS AFINS: UM ESTUDO NAS \\ UNIVERSIDADES POTIGUARES À LUZ DO CURRÍCULO MUNDIAL \\ DOI: http://dx.doi.org/10.5007/1983-4535.2017v10n3p248}

analisar as ementas dos conhecimentos sobre Tópicos Contemporâneos, percebeu-se que as mesmas apresentam poucas ou quase nenhum tipo de informação sobre o conteúdo a ser ministrado em sala de aula. Isso porque, normalmente essas ementas são mais genéricas, deixando a critério do professor responsável por ela, deliberar sobre o conteúdo a ser ministrado.

Tabela 4 Distribuição dos conhecimentos no módulo de Contabilidade Financeira Avançada

\begin{tabular}{|c|c|c|c|c|c|c|c|c|c|c|c|}
\hline \multirow{2}{*}{ CONHECIMENTOS } & \multirow{2}{*}{$\mathrm{CC}$} & \multicolumn{2}{|c|}{ UFERSA } & \multicolumn{2}{|c|}{ UERN } & \multicolumn{2}{|c|}{ UFRN } & \multicolumn{2}{|c|}{ UnP } & \multicolumn{2}{|c|}{ TOTAL } \\
\hline & & $f$ & $\%$ & $f$ & $\%$ & $f$ & $\%$ & $f$ & $\%$ & $f$ & $\%$ \\
\hline \multirow{3}{*}{$\begin{array}{l}\text { Contabilidade } \\
\text { Avançada Aplicada }\end{array}$} & OB & 7 & 58,3 & 2 & 25,0 & 12 & 75,0 & 0 & 0,0 & \multirow{3}{*}{29} & \multirow{3}{*}{74,4} \\
\hline & OP & 1 & 8,3 & 3 & 37,5 & 3 & 18,8 & 1 & 33,3 & & \\
\hline & Total & 8 & - & 5 & - & 15 & - & 1 & - & & \\
\hline \multirow{3}{*}{$\begin{array}{l}\text { Tópicos } \\
\text { Contemporâneos }\end{array}$} & $\mathrm{OB}$ & 2 & 16,7 & 0 & 0,0 & 1 & 6,3 & 2 & 66,7 & \multirow{3}{*}{10} & \multirow{3}{*}{25,6} \\
\hline & OP & 2 & 16,7 & 3 & 37,5 & 0 & 0,0 & 0 & 0,0 & & \\
\hline & Total & 4 & - & 3 & - & 1 & - & 2 & - & & \\
\hline TOTAL $(f)$ & - & \multicolumn{2}{|c|}{12} & \multicolumn{2}{|c|}{8} & \multicolumn{2}{|c|}{16} & \multicolumn{2}{|c|}{3} & \multicolumn{2}{|c|}{39} \\
\hline
\end{tabular}

Fonte: Dados da pesquisa (2014).

Cabe frisar que entre as IES pesquisadas, quando se trata do módulo de Contabilidade Financeira Avançada, o currículo da UERN destina poucos pontos de discussão sobre os Tópicos Contemporâneos (3). Além disso, destaca-se que os mesmos são tratados, predominantemente, em componentes optativos, o que não garante uma ampla discussão entre os discentes em formação, sobre as mudanças ocorridas no ambiente contábil. Já na UnP, observa-se que algo semelhante quando se trata de conhecimentos sobre Contabilidade Avançada Aplicada (1). Por conseguinte, demanda-se o alinhamento do PPC das IES pesquisa, não só as questões de regionalidade, mas também aos conteúdos, habilidades e competências requeridas pelo campo de atuação profissional (RÊGO; ANDRADE, 2010) e o CM.

Em se tratando do módulo de Contabilidade Gerencial, que contempla conteúdos essenciais para o processo de análise e tomada de decisão, constatou-se uma maior preocupação com os conhecimentos sobre Contabilidade de Custos $(48,5 \%)$, como pode ser visualizado na Tabela 5. Isso corrobora com o conteúdo programático do Exame de Suficiência do CFC, que nas edições de 2007 a 2012, contemplou cerca de 70 questões sobre o assunto (HEIN; KOTTWITZ; WISSMANN, 2012). Destaca-se que o referido módulo subsidia o processo de análise e tomada de decisão em nível gerencial, abordando tanto questões inerentes às políticas internas, como as atividades que devem ser continuadas ou descontinuadas ao longo do tempo. 


\section{OS CONHECIMENTOS BÁSICOS DE CONTABILIDADE E ÁREAS AFINS: UM ESTUDO NAS \\ UNIVERSIDADES POTIGUARES À LUZ DO CURRÍCULO MUNDIAL \\ DOI: http://dx.doi.org/10.5007/1983-4535.2017v10n3p248}

Tabela 5 Distribuição dos conhecimentos no módulo de Contabilidade Gerencial

\begin{tabular}{|c|c|c|c|c|c|c|c|c|c|c|c|}
\hline \multirow{2}{*}{ CONHECIMENTOS } & \multirow{2}{*}{$\mathbf{C C}$} & \multicolumn{2}{|c|}{ UFERSA } & \multicolumn{2}{|c|}{ UERN } & \multicolumn{2}{|c|}{ UFRN } & \multicolumn{2}{|c|}{ UnP } & \multicolumn{2}{|c|}{ TOTAL } \\
\hline & & $f$ & $\%$ & $f$ & $\%$ & $f$ & $\%$ & $f$ & $\%$ & $f$ & $\%$ \\
\hline \multirow{3}{*}{$\begin{array}{l}\text { Análise de Balanços } \\
\text { Avançados }\end{array}$} & OB & 6 & 18,8 & 3 & 15,0 & 7 & 21,2 & 2 & 16,7 & \multirow{3}{*}{21} & \multirow{3}{*}{21,6} \\
\hline & OP & 0 & 0,0 & 2 & 10,0 & 1 & 3,0 & 0 & 0,0 & & \\
\hline & Total & 6 & - & 5 & - & 8 & - & 2 & - & & \\
\hline \multirow{3}{*}{ Análise de Custos } & $\mathrm{OB}$ & 5 & 15,6 & 1 & 5,0 & 11 & 33,3 & 4 & 33,3 & \multirow{3}{*}{29} & \multirow{3}{*}{29,9} \\
\hline & OP & 5 & 15,6 & 3 & 15,0 & 0 & 0,0 & 0 & 0,0 & & \\
\hline & Total & 10 & - & 4 & - & 11 & - & 4 & - & & \\
\hline \multirow{3}{*}{$\begin{array}{l}\text { Contabilidade de } \\
\text { Custos }\end{array}$} & OB & 15 & 46,9 & 11 & 55,0 & 13 & 39,4 & 6 & 50,0 & \multirow{3}{*}{47} & \multirow{3}{*}{48,5} \\
\hline & OP & 1 & 3,1 & 0 & 0,0 & 1 & 3,0 & 0 & 0,0 & & \\
\hline & Total & 16 & - & 11 & - & 14 & - & 6 & - & & \\
\hline TOTAL $(f)$ & - & \multicolumn{2}{|c|}{32} & \multicolumn{2}{|c|}{20} & \multicolumn{2}{|c|}{33} & \multicolumn{2}{|c|}{12} & \multicolumn{2}{|c|}{97} \\
\hline
\end{tabular}

Fonte: Dados da pesquisa (2014).

Destaca-se que quando se tratam dos conhecimentos inerentes a Contabilidade de Custos, o termo mais recorrente volta-se ao tratamento e aplicação das metodologias de "custeio". Isso revela que predomina a inclusão de discussões sobre os métodos trabalhos em sala de aula, como o: absorção, variável e por atividades. Outro termo recorrente, diz respeito à questão da "precificação", que constitui um conteúdo comum, quando se trata da definição do preço de venda de um produto ou serviço, que se encontra em processo de negociação.

Considerando o conteúdo ministrado em cada IES, a UERN se destaca por concentrar, no módulo de Contabilidade Gerencial, amplos conhecimentos sobre Contabilidade de Custos, entre os componentes obrigatórios (55,0\%). Na UFERSA, UFRN e UnP, observa-se que os conhecimentos sobre Análise de Balanços Avançados (18,8\%; 21,1\%; 16,7\%) e Análises de Custos $(15,6 \% ; 33,3 \% ; 33,3 \%)$ são, predominantemente, contemplados entre os componentes obrigatórios.

No que diz respeito ao módulo de Fundamentos de Auditoria, que engloba aspectos normativos, princípios e ações a serem desenvolvidos por profissionais com formação em contabilidade, os dados revelam que nenhuma IES discute sobre o processo de Auditoria de Sistemas Informatizados, como ilustrado na Tabela 6. Segundo Gonçalves et al. (2007), esse tipo de conhecimento é essencial para o processo formativo, uma vez que propicia o desenvolvimento de habilidades e competências apropriadas para a avaliação e validação do controle interno de uma organização. Destaca-se que esse tipo de preocupação se deve ao avanço tecnológico e necessidade de inserção de mecanismos de acesso a banco de dados mais confiáveis e seguros. 


\section{OS CONHECIMENTOS BÁSICOS DE CONTABILIDADE E ÁREAS AFINS: UM ESTUDO NAS \\ UNIVERSIDADES POTIGUARES À LUZ DO CURRÍCULO MUNDIAL \\ DOI: http://dx.doi.org/10.5007/1983-4535.2017v10n3p248}

Tabela 6 Distribuição dos conhecimentos no módulo de Fundamentos de Auditoria

\begin{tabular}{|c|c|c|c|c|c|c|c|c|c|c|c|}
\hline \multirow{2}{*}{ CONHECIMENTOS } & \multirow{2}{*}{$\mathrm{CC}$} & \multicolumn{2}{|c|}{ UFERSA } & \multicolumn{2}{|c|}{ UERN } & \multicolumn{2}{|c|}{ UFRN } & \multicolumn{2}{|c|}{ UnP } & \multicolumn{2}{|c|}{ TOTAL } \\
\hline & & $f$ & $\%$ & $f$ & $\%$ & $f$ & $\%$ & $f$ & $\%$ & $f$ & $\%$ \\
\hline \multirow{3}{*}{$\begin{array}{l}\text { Auditoria de } \\
\text { Sistemas } \\
\text { Informatizados }\end{array}$} & $\mathrm{OB}$ & 0 & 0,0 & 0 & 0,0 & 0 & 0,0 & 0 & 0,0 & \multirow{3}{*}{$\mathbf{0}$} & \multirow{3}{*}{0,0} \\
\hline & $\mathrm{OP}$ & 0 & 0,0 & 0 & 0,0 & 0 & 0,0 & 0 & 0,0 & & \\
\hline & Total & $\mathbf{0}$ & - & $\mathbf{0}$ & - & $\mathbf{0}$ & - & $\mathbf{0}$ & - & & \\
\hline \multirow{3}{*}{$\begin{array}{l}\text { Avaliação e } \\
\text { Planejamento de } \\
\text { Auditoria }\end{array}$} & $\mathrm{OB}$ & 11 & 42,3 & 6 & 60,0 & 11 & 68,8 & 4 & 57,1 & \multirow{3}{*}{32} & \multirow{3}{*}{54,2} \\
\hline & $\mathrm{OP}$ & 0 & 0,0 & 0 & 0,0 & 0 & 0,0 & 0 & 0,0 & & \\
\hline & Total & 11 & - & 6 & - & 11 & - & 4 & - & & \\
\hline \multirow{3}{*}{$\begin{array}{l}\text { Normas Nacionais e } \\
\text { Internacionais de } \\
\text { Auditoria }\end{array}$} & $\mathrm{OB}$ & 4 & 15,4 & 1 & 10,0 & 2 & 12,5 & 1 & 14,3 & \multirow{3}{*}{8} & \multirow{3}{*}{13,6} \\
\hline & OP & 0 & 0,0 & 0 & 0,0 & 0 & 0,0 & 0 & 0,0 & & \\
\hline & Total & 4 & - & 1 & - & 2 & - & 1 & - & & \\
\hline \multirow{3}{*}{$\begin{array}{l}\text { Princípios e } \\
\text { Conceitos de } \\
\text { Auditoria } \\
\end{array}$} & OB & 11 & 42,3 & 1 & 10,0 & 3 & 18,8 & 2 & 28,6 & \multirow{3}{*}{19} & \multirow{3}{*}{32,2} \\
\hline & $\mathrm{OP}$ & 0 & 0,0 & 2 & 20,0 & 0 & 0,0 & 0 & 0,0 & & \\
\hline & Total & 11 & - & 3 & - & 3 & - & 2 & - & & \\
\hline TOTAL $(f)$ & & \multicolumn{2}{|c|}{26} & & \multicolumn{2}{|c|}{16} & & \\
\hline
\end{tabular}

Fonte: Dados da pesquisa (2014).

Quanto aos conhecimentos inerentes a Avaliação e Planejamento de Auditoria, os dados apontam que todas as IES discutem sobre o assunto, essencialmente entre os componentes de cunho obrigatório. A UERN (60,0\%) e UFRN $(68,8 \%)$ se destacam por concentrar grande parte de suas discussões ao redor do assunto, contemplando questões inerentes ao controle e tramitação do fluxo de dados da organização. Os dados também indicam que a UERN, canaliza grande parte de seus esforços, sobre o tratamento dos Princípios e Conceitos de Auditoria, entre os componentes optativos (20,0\%), o que pode levar os discentes a terem pouco fundamento sobre o assunto.

Considerando as mudanças advindas com o processo de convergência as normas internacionais e criação do CPC, as IES pesquisadas se preocupam em destinar parte de seu tempo para debater sobre o assunto, entre os componentes obrigatórios. Em se tratando do módulo de Integração dos Conhecimentos, que trata sobre o desenvolvimento de Estudos de Casos, em sala de aula, os dados apontam que esse tipo de conhecimento é essencialmente explicado entre os componentes optativos, como pode ser visualizado na Tabela 7. Para Marion, Garcia e Cordeiro (1999), esse tipo de estratégia de ensino parte da contextualização de um problema, sendo válido quando há compatibilidade com o conhecimento do discente. 


\section{OS CONHECIMENTOS BÁSICOS DE CONTABILIDADE E ÁREAS AFINS: UM ESTUDO NAS \\ UNIVERSIDADES POTIGUARES À LUZ DO CURRÍCULO MUNDIAL \\ DOI: http://dx.doi.org/10.5007/1983-4535.2017v10n3p248}

Tabela 7 Distribuição dos conhecimentos no módulo de Integração dos Conhecimentos

\begin{tabular}{|c|c|c|c|c|c|c|c|c|c|c|c|}
\hline \multirow{2}{*}{ CONHECIMENTOS } & \multirow{2}{*}{$\mathrm{CC}$} & \multicolumn{2}{|c|}{ UFERSA } & \multicolumn{2}{|c|}{ UERN } & \multicolumn{2}{|c|}{ UFRN } & \multicolumn{2}{|c|}{ UnP } & \multicolumn{2}{|c|}{ TOTAL } \\
\hline & & $f$ & $\%$ & $F$ & $\%$ & $f$ & $\%$ & $f$ & $\%$ & $f$ & $\%$ \\
\hline \multirow{3}{*}{ Estudos de Casos } & OB & 0 & 0,0 & 1 & 10,0 & 0 & 0,0 & 0 & 0,0 & \multirow{3}{*}{19} & \multirow{3}{*}{100} \\
\hline & OP & 8 & $\begin{array}{c}100 \\
0\end{array}$ & 9 & 90,0 & 1 & $\begin{array}{c}100 \\
0\end{array}$ & 0 & 0,0 & & \\
\hline & Total & 8 & - & 10 & - & 1 & - & $\mathbf{0}$ & - & & \\
\hline TOTAL $(f)$ & - & \multicolumn{2}{|c|}{8} & \multicolumn{2}{|c|}{10} & \multicolumn{2}{|c|}{1} & \multicolumn{2}{|c|}{ 0 } & \multicolumn{2}{|c|}{19} \\
\hline
\end{tabular}

Fonte: Dados da pesquisa (2014).

Ponderando sobre o conteúdo proposto pelo CM, observa-se que há certa distorção entre a disponibilidade desse tipo de componente, como obrigatório, no processo formativo e o que é praticado pelas IES potiguares. A UERN e a UFERSA demonstram incluir esse tipo de estratégia de ensino, que contribui para a formação do senso crítico dos discentes, aliando teoria e prática (MARION; GARCIA; CORDEIRO, 1999), predominantemente, entre os componentes optativos. Apesar de haver discussões quanto à sua eficiência das estratégias de ensino-aprendizagem existentes (CARMO; BARROSO; ALBERTIN, 2010), essa constatação é preocupante, uma vez que as habilidades e competências dos discentes ficam limitadas a situações específicas, o que dificulta a integração entre os conteúdos desenvolvidos em sala.

Os dados referentes ao módulo de Legislação Comercial apontam que as IES tem se preocupado em discutir sobre os aspectos legais, que fundamentam os tramites das operações desenvolvidas pelas empresas, como ilustrado na Tabela 8. Quando se trata das regras que norteiam as práticas de comércio, observa-se que as IES destinam uma atenção especial, entre os componentes obrigatórios, para tratar sobre os conhecimentos na área de Direito Comercial e Direito Público e Privado.

Tabela 8 Distribuição dos conhecimentos no módulo de Legislação Comercial

\begin{tabular}{|c|c|c|c|c|c|c|c|c|c|c|c|}
\hline \multirow{2}{*}{ CONHECIMENTOS } & \multirow{2}{*}{$\mathrm{CC}$} & \multicolumn{2}{|c|}{ UFERSA } & \multicolumn{2}{|c|}{ UERN } & \multicolumn{2}{|c|}{ UFRN } & \multicolumn{2}{|c|}{ UnP } & \multicolumn{2}{|c|}{ TOTAL } \\
\hline & & $f$ & $\%$ & $F$ & $\%$ & $f$ & $\%$ & $f$ & $\%$ & $f$ & $\%$ \\
\hline \multirow{3}{*}{ Direito Comercial } & OB & 9 & 36,0 & 7 & 16,7 & 9 & 40,9 & 10 & 34,5 & \multirow{3}{*}{41} & \multirow{3}{*}{34,7} \\
\hline & OP & 0 & 0,0 & 5 & 11,9 & 1 & 4,5 & 0 & 0,0 & & \\
\hline & Total & 9 & - & 12 & - & 10 & - & 10 & - & & \\
\hline \multirow{3}{*}{$\begin{array}{l}\text { Direito Público e } \\
\text { Privado }\end{array}$} & OB & 2 & 8,0 & 4 & 9,5 & 4 & 18,2 & 10 & 34,5 & \multirow{3}{*}{33} & \multirow{3}{*}{28,0} \\
\hline & OP & 0 & 0,0 & 6 & 14,3 & 1 & 4,5 & 6 & 20,7 & & \\
\hline & Total & 2 & - & 10 & - & 5 & - & 16 & - & & \\
\hline \multirow{3}{*}{$\begin{array}{l}\text { Legislação } \\
\text { Social/Trabalhista }\end{array}$} & OB & 13 & 52,0 & 6 & 14,3 & 5 & 22,7 & 3 & 10,3 & \multirow{3}{*}{36} & \multirow{3}{*}{30,5} \\
\hline & $\mathrm{OP}$ & 0 & 0,0 & 9 & 21,4 & 0 & 0,0 & 0 & 0,0 & & \\
\hline & Total & 13 & - & 15 & - & 5 & - & 3 & - & & \\
\hline \multirow{3}{*}{ Legislação Societária } & OB & 1 & 4,0 & 1 & 2,4 & 2 & 9,1 & 0 & 0,0 & \multirow{3}{*}{8} & \multirow{3}{*}{6,8} \\
\hline & $\mathrm{OP}$ & 0 & 0,0 & 4 & 9,5 & 0 & 0,0 & 0 & 0,0 & & \\
\hline & Total & 1 & - & 5 & - & 2 & - & $\mathbf{0}$ & - & & \\
\hline TOTAL $(f)$ & - & \multicolumn{2}{|c|}{25} & \multicolumn{2}{|c|}{42} & \multicolumn{2}{|c|}{22} & \multicolumn{2}{|c|}{29} & \multicolumn{2}{|c|}{118} \\
\hline
\end{tabular}

Fonte: Dados da pesquisa (2014). 


\section{OS CONHECIMENTOS BÁSICOS DE CONTABILIDADE E ÁREAS AFINS: UM ESTUDO NAS \\ UNIVERSIDADES POTIGUARES À LUZ DO CURRÍCULO MUNDIAL \\ DOI: http://dx.doi.org/10.5007/1983-4535.2017v10n3p248}

Outro ponto que chama atenção no referido módulo, diz respeito aos conhecimentos na área de Legislação Social/Trabalhista, que são abordadas em todas as IES, como componente obrigatório. Isso garante aos discentes o aprofundamento, teórico e normativo, necessário para orientar os empresários sobre como deve proceder durante o processo de contratação e demissão de colaboradores.

Destaca-se que apesar das mudanças ocorridas na área societária, os dados revelam que pouco se discute sobre os conhecimentos inerentes a Legislação Societária, o que é preocupante, considerando um processo formativo global, que possa transcender questões de regionalidade. Apesar disso, destaca-se que a atualização e desenvolvimento de debates sobre o assunto é importante para o processo formativo, uma vez que habilita o profissional de Contabilidade a adotar práticas legais de negócio.

Analisando o módulo de Sistema de Informação Contábil, observa-se na Tabela 9, que somente a UERN (1) e UnP (2) discutem, timidamente, sobre os conhecimentos inerentes ao Desenvolvimento de Sistemas de Informação Contábil. A ausência de conteúdos dessa natureza prejudica o andamento das atividades de registro e tramitação dos atuais sistemas requerido pelos Poder Público, como o Sistema Público de Escrituração Digital (SPED/2004) e o Sistema de Escrituração Fiscal Digital das Obrigações Fiscais, Previdenciárias e Trabalhistas. (PINHEIRO et al., 2015).

Tabela 9 Distribuição dos conhecimentos no módulo de Sistemas de Informação Contábil

\begin{tabular}{|c|c|c|c|c|c|c|c|c|c|c|c|}
\hline \multirow{2}{*}{ CONHECIMENTOS } & \multirow{2}{*}{$\mathrm{CC}$} & \multicolumn{2}{|c|}{ UFERSA } & \multicolumn{2}{|c|}{ UERN } & \multicolumn{2}{|c|}{ UFRN } & \multicolumn{2}{|c|}{ UnP } & \multicolumn{2}{|c|}{ TOTAL } \\
\hline & & $f$ & $\%$ & $f$ & $\%$ & $f$ & $\%$ & $f$ & $\%$ & $f$ & $\%$ \\
\hline \multirow{3}{*}{$\begin{array}{l}\text { Desenvolvimento de } \\
\text { Sistemas de } \\
\text { Informação Contábil }\end{array}$} & OB & 0 & 0,0 & 0 & 0,0 & 0 & 0,0 & 0 & 0,0 & \multirow{3}{*}{3} & \multirow{3}{*}{5,3} \\
\hline & OP & 0 & 0,0 & 1 & 6,3 & 0 & 0,0 & 2 & 11,1 & & \\
\hline & Total & $\mathbf{0}$ & - & 1 & - & $\mathbf{0}$ & - & 2 & - & & \\
\hline \multirow{3}{*}{$\begin{array}{l}\text { Funcionamento dos } \\
\text { Prog. Informáticos } \\
\text { Comerciais }\end{array}$} & OB & 1 & 12,5 & 3 & 18,8 & 1 & 6,7 & 1 & 5,6 & \multirow{3}{*}{6} & \multirow{3}{*}{10,5} \\
\hline & OP & 0 & 0,0 & 0 & 0,0 & 0 & 0,0 & 0 & 0,0 & & \\
\hline & Total & 1 & - & 3 & - & 1 & - & 1 & - & & \\
\hline \multirow{3}{*}{$\begin{array}{l}\text { Sistemas de } \\
\text { Informações } \\
\text { Gerenciais }\end{array}$} & $\mathrm{OB}$ & 3 & 37,5 & 8 & 50,0 & 12 & 80,0 & 11 & 61,1 & \multirow{3}{*}{48} & \multirow{3}{*}{84,2} \\
\hline & $\mathrm{OP}$ & 4 & 50,0 & 4 & 25,0 & 2 & 13,3 & 4 & 22,2 & & \\
\hline & Total & 7 & - & 12 & - & 14 & - & 15 & - & & \\
\hline TOTAL $(f)$ & - & \multicolumn{2}{|c|}{8} & \multicolumn{2}{|c|}{16} & \multicolumn{2}{|c|}{15} & \multicolumn{2}{|c|}{18} & \multicolumn{2}{|c|}{57} \\
\hline
\end{tabular}

Fonte: Dados da pesquisa (2014).

No que diz respeito aos conhecimentos sobre o Funcionamento dos Programas Informáticos Comerciais, os dados revelam que todas as IES potiguares, se utilizam de algum tipo de software, já comercializado no mercado e adotado nos Escritórios de Contabilidade, como fonte de ensino-aprendizagem. Os mesmos são apresentados como instrumento de 


\section{OS CONHECIMENTOS BÁSICOS DE CONTABILIDADE E ÁREAS AFINS: UM ESTUDO NAS \\ UNIVERSIDADES POTIGUARES À LUZ DO CURRÍCULO MUNDIAL \\ DOI: http://dx.doi.org/10.5007/1983-4535.2017v10n3p248}

ensino, em componentes curriculares obrigatórios o que garante o acesso, ainda durante o processo formativo, as atividades práticas inerentes ao campo de atuação profissional. Isso corrobora com a concepção de estratégias que aliam teoria e prática, em um ambiente seguro, com tutoria e respaldo para a resolução de situações-problemas reproduzidas com base nas rotinas de trabalho do Contador (PINHEIRO et al., 2015).

Os conhecimentos sobre Sistemas de Informações Gerenciais são explorados em todas as IES, como medida essencial para o processo de tomada de decisão, com destaque para os conteúdos discutidos na UFRN (80,0\%) e UnP (61,1\%). O mesmo trata-se de um conteúdo emergente e importante para o campo de atuação profissional do Contador, especialmente quando se trata do suporte ao processo de tomada de decisão.

Ponderando sobre o conteúdo do módulo de Tributação, apresentado na Tabela 10, os dados apontam que todas as IES discutem sobre o assunto, nos componentes de cunho obrigatório. Quando se trata dos conhecimentos pertinentes a Contabilidade Tributária, observa-se que a UnP, dedica grande parte de seus esforços para tratar sobre o processo de contabilização dos tributos. Para Nazário, Mendes e Aquino (2008), esse conteúdo é essencial para o processo formativo, uma vez que prepara os discentes para o exercício profissional e o desenvolvimento de políticas capazes de propiciar a elisão físcal.

Tabela 10 Distribuição dos conhecimentos no módulo de Tributação

\begin{tabular}{|c|c|c|c|c|c|c|c|c|c|c|c|}
\hline \multirow{2}{*}{ CONHECIMENTOS } & \multirow{2}{*}{$\mathrm{CC}$} & \multicolumn{2}{|c|}{ UFERSA } & \multicolumn{2}{|c|}{ UERN } & \multicolumn{2}{|c|}{ UFRN } & \multicolumn{2}{|c|}{ UnP } & \multicolumn{2}{|c|}{ TOTAL } \\
\hline & & $f$ & $\%$ & $f$ & $\%$ & $f$ & $\%$ & $f$ & $\%$ & $f$ & $\%$ \\
\hline \multirow{3}{*}{$\begin{array}{l}\text { Contabilidade } \\
\text { Tributária }\end{array}$} & OB & 6 & 28,6 & 8 & 33,3 & 9 & 36,0 & 11 & 73,3 & \multirow{3}{*}{36} & \multirow{3}{*}{42,4} \\
\hline & $\mathrm{OP}$ & 0 & 0,0 & 2 & 8,3 & 0 & 0,0 & 0 & 0,0 & & \\
\hline & Total & 6 & - & 10 & - & 9 & - & 11 & - & & \\
\hline \multirow{3}{*}{ Direito Tributário } & OB & 15 & 71,4 & 7 & 29,2 & 14 & 56,0 & 4 & 26,7 & \multirow{3}{*}{49} & \multirow{3}{*}{57,6} \\
\hline & $\mathrm{OP}$ & 0 & 0,0 & 7 & 29,2 & 2 & 8,0 & 0 & 0,0 & & \\
\hline & Total & 15 & - & 14 & - & 16 & - & 4 & - & & \\
\hline TOTAL $(f)$ & - & \multicolumn{2}{|c|}{21} & \multicolumn{2}{|c|}{24} & \multicolumn{2}{|c|}{25} & \multicolumn{2}{|c|}{15} & \multicolumn{2}{|c|}{85} \\
\hline
\end{tabular}

Fonte: Dados da pesquisa (2014).

A UFERSA se destaca por concentrar, entre seus componentes obrigatórios, conhecimentos aprofundados sobre Direito Tributário $(71,4 \%)$, entretanto pouco conteúdo de contabilidade tributária. Realidade inversa ocorre na UnP. Na UERN os conteúdos possuem quase mesmo percentual. A UFRN, assim como a UFERSA, privilegia o conteúdo da área de direito ao de contabilidade.

Quanto à aderência global das IES pesquisadas ao CM, apresenta-se a Tabela 11. 


\section{OS CONHECIMENTOS BÁSICOS DE CONTABILIDADE E ÁREAS AFINS: UM ESTUDO NAS \\ UNIVERSIDADES POTIGUARES À LUZ DO CURRÍCULO MUNDIAL \\ DOI: http://dx.doi.org/10.5007/1983-4535.2017v10n3p248}

Tabela 11 Nível de aderência dos conteúdos ministrados nas IES potiguares

\begin{tabular}{|c|c|c|c|c|c|c|c|c|}
\hline \multirow{2}{*}{ COMPONENTES } & \multicolumn{2}{|c|}{ UFERSA } & \multicolumn{2}{|c|}{ UERN } & \multicolumn{2}{|c|}{ UFRN } & \multicolumn{2}{|c|}{ UnP } \\
\hline & $f$ & $\%$ & $f$ & $\%$ & $f$ & $\%$ & $f$ & $\%$ \\
\hline Obrigatórios & 197 & 89,5 & 119 & 56,1 & 200 & 93,0 & 124 & 87,9 \\
\hline Optativos & 23 & 10,5 & 93 & 43,9 & 15 & 7,0 & 17 & 12,1 \\
\hline TOTAL $(f)$ & \multicolumn{2}{|c|}{220} & \multicolumn{2}{|c|}{212} & \multicolumn{2}{|c|}{215} & \multicolumn{2}{|c|}{141} \\
\hline
\end{tabular}

Fonte: Dados da pesquisa (2014).

Considerando o conteúdo das ementas analisadas e os termos encontrados, analisou-se o nível de aderência das IES ao CM. Nessa conjuntura, os dados revelam que dos 788 termos identificados, em termos de similaridade, que a UFERSA $(27,92 \%)$ é a que mais se aproxima do CM, diferentemente do que é observado na UnP (17,89\%).

\section{CONSIDERAÇÕES FINAIS E RECOMENDAÇÕES}

O presente estudo se objetivou apresentar um panorama sobre o conteúdo ministrado pelas universidades potiguares, à luz do CM proposto pela ONU/UNCTAD/ISAR. Para tanto, fez uso da análise documental e de conteúdo das ementas de componentes curriculares, obrigatórios e optativos, dos cursos de graduação em Ciências Contábeis, das IES norte-riograndenses. Tudo isso, de modo a permitir fazer um contraponto entre o que as mesmas discutem em sala de aula e os conhecimentos sugeridos em cada módulo do Bloco CBCAA.

O estudo aponta que as IES potiguares concentram a maior parte de seus esforços na disseminação de conhecimentos referentes aos módulos de Contabilidade Básica (21,8\%), Contabilidade Financeira $(18,0 \%)$ e Legislação Comercial (15,0\%). Isso sugere o desenvolvimento de ações que permitam discutir, mais criticamente, sobre questões inerentes ao processo de reconhecimento, mensuração e evidenciação das variações patrimoniais. Nessa conjuntura, inclusão de pontos convergentes as normas internacionais e práticas de auditoria, tornam-se um elemento essencial para o avanço da Contabilidade, em si, e do processo de ensino-aprendizagem.

A inclusão de temáticas emergentes, como Contabilidade Ambiental, Tópicos Contemporâneos, Auditoria de Sistemas Informatizados e Desenvolvimento de Sistemas de Informação Contábil, tende a ampliar as possibilidades de atuação dos egressos. Além disso, discussões envolvendo Estudos de Caso também podem enriquecer o processo formativo, aliando teoria e prática, bem como desenvolver o senso crítico dos discentes para a resolução de situações-problema. 
Mesmo considerando a relevância dos achados dessa pesquisa, especialmente, por propiciar a discussão sobre os currículos dos Cursos de Ciências Contábeis, a mesma apresenta limita-se a traçar um panorama sobre o conteúdo das ementas e o CM. Além disso, considerando a dinamicidade do ambiente e necessidade de mudanças no PPC dos cursos, alguns aspectos abordados já podem está em tramitação das IES pesquisadas, vislumbrando a adequação ao CM. Logo, sugere-se o desenvolvimento de estudos que amplie o número de IES pesquisadas e inclua os indicadores de avaliação, com o intuito de avaliar as estratégias e práticas de ensino adotadas.

\section{REFERÊNCIAS}

ALBUQUERQUE, L. S.; CARVALHO, J. R. M. Uma investigação sobre as perspectivas dos formandos de ciências contábeis em relação ao mercado de trabalho: o caso de uma IES pública no Estado do Rio Grande do Norte. Revista Enfoque: reflexão contábil, Maringá, v. 26, n. 1, p. 9-16, jan./abr. 2007.

ANTUNES, M. T. P. et al. A adoção no Brasil das normas internacionais de contabilidade IFRS: o processo e seus impactos na qualidade da informação contábil. Revista de Economia \& Relações Internacionais, São Paulo, v. 10, n. 20, p. 5-193, jan. 2012.

BARDIN, L. Análise de Conteúdo. Lisboa: Edições 70, LDA, 2009.

BRASIL. Lei no 9.394/1996. Estabelece as Diretrizes e Bases da Educação Nacional. Disponível em: http://www.planalto.gov.br/CCIVIL_03/leis/L9394.htm. Acesso em: 10 out. 2013.

BRASIL. Ministério da Educação. Resolução CNE/CSE n. ${ }^{\circ}$ 10/2004. Institui as Diretrizes Curriculares Nacionais para o Curso de Graduação em Ciências Contábeis, bacharelado, e dá outras providências. Disponível em:

http://portal.mec.gov.br/cne/arquivos/pdf/rces10_04.pdf. Acesso em: 10 out. 2013.

CAMPOS, L. C.; LEMES, S. Análise comparativa entre o Currículo Mundial proposto pela ONU/UNCTAD/ISAR e as universidades federais do Estado de Minas Gerais. Administração: Ensino e Pesquisa, Rio de Janeiro, v.15, n. 1, p. 145-182, jan./mar. 2012.

CARMO, B. B. T.; BARRoso, S. H. A.; ALBERTIN, M. R. Aprendizagem discente e estratégia docente: metodologias para maximizar o aprendizado no Curso de Engenharia de Produção. Revista Produção On-line, Florianópolis, v. 10, n. 4, p. 779-817, dez. 2010.

CAVALCANTE, D. S. et al. Adequação dos currículos dos cursos de contabilidade das universidades federais brasileiras ao Currículo Mundial de contabilidade e o desempenho no Enade. Pensar Contábil, Rio de Janeiro, v. 13, n. 50, p. 42 - 52, jan./abr. 2011. 
CFC. Conselho Federal de Contabilidade. Resolução n. ${ }^{\text {o }}$ 560/1983. Dispõe sobre as prerrogativas profissionais. Disponível em:

http://www.cfc.org.br/sisweb/sre/detalhes_sre.aspx?Codigo=1983/000560. Acesso em: 10 jul. 2013.

CZESNAT, A. O.; CUNHA, J. V. A.; DOMINGUES, M. J. C. S. Análise comparativa entre os currículos dos cursos de ciências contábeis das universidades do Estado de Santa Catarina listadas pelo MEC e o currículo Mundial proposto pela ONU/UNCTAD/ISAR. Gestão \& Regionalidade, São Caetano do Sul, v. 25, n. 75, p. 22-30, set./dez. 2009.

ERFURTH, A. E.; DOMINGUES, M. J. C. S. Estrutura curricular do curso de ciências contábeis na universidade de Buenos Aires versus a estrutura curricular proposta pelo ISAR/UNCTAD. In: Seminário de Ciências Contábeis FURB, 4, 2008, Blumenau, Anais eletrônicos... FURB: Blumenau, 2008.

FARIA, A. C.; QUEIROZ, M. R. B. Demanda de profissionais habilitados em Contabilidade Internacional no mercado de trabalho da cidade de São Paulo. Revista Universo Contábil, Blumenau, v. 5, n. 1, p. 55-71, jan./mar. 2009.

FERNANDES, B. V. R. et al. Análise da percepção dos docentes dos cursos de graduação em ciências contábeis do Brasil quanto ao processo de convergência às normas internacionais de contabilidade aplicadas no Brasil. Revista de Contabilidade e Controladoria, Curitiba, v. 3, n. 3, p. 24 - 50, set./dez. 2011.

GIL, A. C. Como elaborar projetos de pesquisa. 4. ed. São Paulo: Atlas, 2002.

GONÇALVES, V. L. et al. Auditoria de sistemas contábeis: um estudo sobre os impactos advindos do avanço tecnológico em empresas de Auditoria no Estado de Pernambuco. In: Seminário UFPE de Ciências Contábeis, 1, 2007, Recife. Anais eletrônicos... Seminário UFPE: Recife, 2007.

GUimarães, I. P. et al. Nível de percepção do Projeto Político-Pedagógico: o que pensam os profissionais de educação contábil de uma Instituição de Ensino Superior Pública do Estado da Bahia/Brasil. Revista de Contabilidade da UFBA, Salvador, v. 4, n. 3, p. 4-19, set./dez. 2010.

GUimarães, I. P. et al. Uma Análise dos Projetos Político Pedagógicos dos cursos de Ciências Contábeis das universidades públicas do Estado da Bahia. In: Congresso Internacional Galego-português de Psicopedagogia, 10, 2009, Braga. Anais eletrônicos... Universidade do Minho: Braga, 2009.

HEIN, A. F.; KOTTWITZ, G.; WISSMANN, M. A. Contabilidade de custos: a relação entre os conteúdos ministrados pelas IES e os conteúdos exigidos no Exame de Suficiência. In: Congresso Brasileiro de Custos, 19, 2012, Bento Gonçalves. Anais eletrônicos... ABC: Bento Gonçalves, 2012.

IUDÍCIBUS, S. Teoria da contabilidade. 7. ed. São Paulo: Atlas, 2004. 
LAFFIN, M. De contador a professor: a trajetória da docência no ensino superior em contabilidade. Florianópolis: Imprensa Universitária, 2005.

MAGAlHÃES, F. A. C.; ANDRADE, J. X. A educação contábil no Estado do Piauí diante da proposta de convergência internacional do currículo de contabilidade concebida pela ONU/UNCTAD/ISAR. In: Congresso USP de Controladoria e Contabilidade, 6, 2006, São Paulo. Anais eletrônicos... USP: São Paulo, 2006.

MARCONI, M. A.; LAKATOS, E. M. Fundamentos de metodologia científica. 5. ed. São Paulo: Atlas, 2003.

MARIN, T. I. S.; LIMA, S. J.; CASA NOVA, S. P. C. Formação do contador - O que o mercado quer, é o que ele tem? In: Congresso USP de Controladoria e Contabilidade, 11, 2011, São Paulo. Anais eletrônicos... São Paulo: USP, 2011.

MARION, J. C.; GARCIA, E.; CORDEIRO, M. Discussão sobre metodologias de ensino aplicáveis à contabilidade. Reuna, Belo Horizonte, v. 1, n. 10, p. 56-64, out. 1999.

MERLO, R. A. O contabilista do século XXI. Jornal do CFC, Brasília, mar./abr. 2006.

NAZÁRIO, N. S.; MENDES, P. C. M.; AQUINO, D. R. B. Percepção dos discentes quanto à importância do conhecimento em Contabilidade Tributária em Instituições de Ensino Superior do Distrito Federal: um estudo empírico. Revista Universo Contábil, Blumenau, v. 4, n. 3, p. 64-81, jul./set. 2008.

NOGUEIRA, V.; FARI, M. A. Perfil do profissional contábil: relações entre formação e atuação no mercado de trabalho. Perspectivas Contemporâneas: revista eletrônica de ciências sociais aplicadas, Campo Mourão, v. 2, n.1, jan./jun. 2007.

OLIVEIRA, C. R. et al. Aproximações entre o perfil do contador desejado pelo mercado e as matrizes curriculares de cursos de graduação em Ciências Contábeis. Revista Eletrônica de Ciências da Educação, Campo Largo, v. 10, n. 1, p .47-68, jul. 2011.

PELEIAS, I. R.; BACCI, J. Pequena cronologia do desenvolvimento contábil no Brasil: os primeiros pensadores, a padronização contábil e os congressos brasileiros de contabilidade. Revista Administração online, São Paulo, v. 5, n. 3, jul./set. 2004.

PELEIAS, I. R. et al. Evolução do ensino da contabilidade no Brasil: uma análise histórica. Revista Contabilidade \& Finanças, São Paulo, Edição 30 anos de Doutorado, p.1932, jun. 2007.

PINHEIRO, O. P. et al. A percepção dos discentes do Curso de graduação em Ciências Contábeis da UFERSA, quanto à adoção de novas ferramentas de ensino-aprendizagem In: Congresso Mossoroense de Contabilidade, 2, 2015, Mossoró. Anais eletrônicos... Congresso UFERSA de Contabilidade: Mossoró, 2015. 
PIRES, C. B.; OTT, E.; DAMACENA, C. “Guarda-Livros" ou "Parceiros de Negócios"? Uma análise do perfil profissional requerido pelo mercado de trabalho para contadores na Região Metropolitana de Porto Alegre (RMPA). Revista Contabilidade Vista \& Revista, Belo Horizonte, v. 20, n. 3, p. 157-187, jul./set. 2009.

RÊGO, T. F.; ANDRADE, E. R. G. Perfil e campo de atuação profissional dos egressos do Curso de Ciências Contábeis da UFRN. Revista Ambiente Contábil, Natal, v. 2, n. 2, p. 1 17, jul./dez. 2010.

RICCIO, E.; SAKATA, M. C. G. Evidências da globalização na educação contábil: estudo das grades curriculares dos cursos de graduação em universidades brasileiras e portuguesas. Revista Contabilidade \& Finanças, São Paulo, v. 15, n. 35, p. 35-44, maio/ago. 2004.

SANTOS, A. C.; DOMINGUES, M. J. C. S.; RIBEIRO, M. J. Um estudo sobre o nível de aderência dos cursos de Ciências Contábeis das Instituições paranaenses listadas no MEC, ao Currículo Mundial. In: Congresso da ANPCONT, 6, 2012, Vitória. Anais eletrônicos... Vitória: ANPCONT, 2012.

SCHMIDT, P. História do pensamento contábil. Porto Alegre: Bookman, 2000.

SEGANTINI, G. T. et al. Uma análise comparativa entre os currículos dos cursos de Ciências contábeis nos países do MERCOSUL com o currículo internacional proposto pela ONU/UNCTAD/ISAR. In: Congresso USP de Iniciação Científica em Contabilidade, 7, 2010, São Paulo. Anais eletrônicos... São Paulo: USP, 2010.

SILVA, E. C. O.; RÊGO, T. F. Proposta formativa versus desempenho: um estudo comparativo entre os cursos de graduação em Ciências Contábeis das IFES brasileiras. Revista Ambiente Contábil, Natal, v. 6, n. 2, p. 55-74, jul./dez. 2014.

UNCTAD. United Nations Conference on Trade and Development. Guideline for a global accounting curriculum and other qualification requirements. 1999.

UNCTAD. United Nations Conference on Trade and Development. Revised model accounting curriculum (MC). Geneva: TD/B/COM.2/ISAR/21, Sep./Oct., 2003.

VALERETTO, G. J. A temática tributária na formação dos Bacharéis em Ciências Contábeis: um estudo comparativo entre os conteúdos das Universidades Federais Brasileiras com a Proposta Nacional do Conselho Federal de ContabilidadeCFC/Fundação Brasileira de Contabilidade-FBC e Proposta do UNCTAD/ISAR. 2010. 157 f. Dissertação (Mestrado em Contabilidade), Universidade Federal do Paraná, Curitiba, 2010.

VEIGA, I. P. A. Educação básica: projeto político-pedagógico; Educação superior: projeto político-pedagógico. Campinas: Papirus, 2004 
VIANA, S. C. P.; SOUSA, J. A. A Internacionalização das Normas Contábeis e a sua relação com os profissionais da área contábil credenciados pelo $\mathrm{CRC}$ na cidade do Natal/RN. Connexio: Revista científica da escola de gestão e negócios, Natal, v. 2, n. 1, p.6578, ago. 2012/jan. 2013.

ZONATTO, V. C. S.; DANI, A. C.; DOMINGUES, M. J. C. S. Análise comparativa entre o currículo mundial proposto pela ONU/UNCTAD/ISAR e os currículos dos Cursos de Graduação presenciais em Ciências Contábeis das Instituições de Ensino Superior do Estado do Rio Grande do Sul listadas pelo MEC. In: Congresso Brasileiro de Custos, 18, 2011, Rio de Janeiro. Anais eletrônicos... Rio de Janeiro: ABC, 2011. 